\title{
Dimensions of Distance Learning for Computer Education
}

\author{
Tony Clear \\ Auckland University of Technology \\ New Zealand \\ Tony.clear@aut.ac.nz \\ Arto Haataja \\ University of Joensuu \\ Finland \\ ahaata@cs.joensuu.fi \\ Jeanine Meyer \\ Pace University \\ USA \\ Jmeyer@pace.edu
}

consciously designed approach informed by a constructivist view

\author{
Jarkko Suhonen \\ University of Joensuu \\ Finland \\ jsuhon@cs.joensuu.fi \\ Stuart Varden \\ Pace University \\ USA \\ svarden@pace.edu
}

\begin{abstract}
In this paper, we explore what is variously termed distance learning (DL), asynchronous, online, Webbased, and Web-supported learning in terms of how it can support and perhaps even improve the fields of education involving computing. We use the term distributed education to cover all mentioned topics. We describe how the incorporation of these methods can benefit computer education. These benefits arise because of the nature of the computing field, the profound requirements for students to understand concepts and acquire skills as opposed to mere exposure to facts, and our assessment that distributed education has the potential to address many of the challenges identified. We conclude with suggestions on the incorporation of distributed methods into computer education.
\end{abstract}

Acknowledgements: Anne Kellerman, SUNY/Binghamton, USA and Joze Rugeli, University of Ljubljana, Slovenia contributed to this paper through participation in an on-line discussion prior to the ITiCSE conference.

\section{Introduction}

A great deal of work and research on distance learning (DL) in its various forms has been conducted in recent years that have lead to an extensive literature $[7,11,13,14,17,18]$. In this paper, we do not attempt to repeat this. Instead we aim to focus on issues that are important to computing education and how effective online delivery can be designed to address the key challenges. We begin with two design and evaluation frameworks and a brief review of supporting technologies. These relate to the dimensions of pedagogy, implementation, and technology. In particular, we believe that a holds the most potential for effective online learning designs. Constructivism in this context refers to the notion that learners must construct their understanding through an active process building on past experiences and knowledge and that knowledge cannot be simply accepted from others. We further argue that hybrid delivery models offer the best fit for the challenges facing computing education today. A totally distance approach, that is, students and teachers separated in location, and/or completely asynchronous approach, students and teachers separated in time, may give way to situations in which faculty create individual forms for each course and situation.

Before continuing, we address briefly the question of what is changing from the standard model of classroom. The traditional lecture classroom model needs improvement and enhancement. It may not meet the challenges which we have identified from our own experience and research and from a survey given at ITiCSE. Though computing departments are undergoing growth in most places because our graduates are in great demand, we still need to improve what we are doing. In particular, commercial forces are attempting to get into the "education business". The ease of delivery and the globalization inherent in the Web means that schools are competing with each other and for-profit enterprises and that competition is worldwide.

Studying and adopting some sort of distance learning approaches can be an incentive for reviewing the objectives of courses and sets of courses in terms of how students actually learn. In particular, it can be a time to become more studentcentered, more attentive and flexible regarding 
individual issues, more current and more open to attending to how students learn. The authors of this report believe that this would lead to constructivist approaches to teaching and learning. This may not be everyone's view. However, we would predict that consideration of new modalities of instruction would bring about healthy revaluation of the status quo. Creating on-line materials and reaching out to existing resources can be ways to re-connect with subject matter that had become old and tired. Taking on the task of creating new forms of courses is a reason to collaborate with colleagues.

In the short term, the novelty of distributed methods may help the process of re-thinking educational objectives and methods because many students and faculty will find this new thing stimulating and fun. The institution will be perceived as "up-to-date", always a good thing in a technological field. Of course, over time, there will need to be more intrinsic merit in the courses.

\section{Dimensions of Distance Learning}

The dimensions of distance learning we focus on refer to pedagogy, implementation and technology.

\subsection{Pedagogy}

In their Evaluation of Information Technology Projects for University Learning Alexander \& Hedberg, [1] note, "The use of a particular information technology did not, in itself, result in improved quality of learning or productivity of learning. Rather a range of factors was identified which are necessary for a successful project outcome, the most critical being the design of the student learning experiences."

Reeves, [11] has proposed a model by which the effective dimensions of an interactive learning system (ILS) may be assessed, which includes "such factors as philosophy, teacher roles and learner control." It provides a useful mechanism by which to review the pedagogical aspects of a learning design. These dimensions may be represented as a point on a continuum between a pair of polar opposites. Assessment of a particular learning design is represented on the continuum for each dimension.

\subsection{Implementation: Models of Distance Learning}

Distance learning can take a number of forms depending on the needs of the target student audience, the educational philosophy of the institution or instructor, and the resources available to both the institution and students.
The Institute for Distance Education of the University of Maryland [16] describes three basic models and their characteristics as follows:

\section{Model A: Distributed Classroom}

\section{Description}

Interactive telecommunications technologies extend a classroom- based course from one location to a group of students at one or more other locations; the typical result is an extended "section" that mixes onsite and distant students. The faculty and institution control the pace and place of instruction.

\section{Characteristics}

Class sessions involve synchronous communication; students and faculty are required to be in a particular place at a particular time (once a week at a minimum). Number of sites varies from two (pointto-point) to five or more (point-to-multipoint); the greater the number of sites, the greater the complexity -- technically, logistically, and perceptually

Students may enrol at sites more convenient to their homes or work locations than the campus. Institutions are able to serve small numbers of students in each location. The nature of the experience mimics that of the classroom for both the instructor and the student.

\section{Example and Rationale}

Strayer University, based in Washington, D.C. and surrounding areas, offers distance courses through its Strayer Online system. Strayer, a regionally accredited institution of higher learning, has chosen a Model A approach in which the instructor teacher from Strayer Online facility in northern Virginia. Class sessions are held at scheduled times and students are required to logon and "check-in" as the instructor takes attendance. Student participation during class sessions is a factor in determining student grades.

The main rationale for selecting the Model A approach is the perceived need on the part of the university to have greater control over the learning process and student outcomes than is typically believed to be available in the Model B Independent Learning approach. Since the university has followed more of a business approach than a traditional academic approach to promote rapid growth, including practices such as no faculty ranks or tenure, no requirement for faculty scholarship, and common syllabi and textbooks 
across all sessions of a course, the university is particularly sensitive to being able to document student outcomes.

\section{Model B: Independent Learning}

\section{Description}

This model frees students from having to be in a particular place at a particular time. Students are provided a variety of materials, including a course guide and detailed syllabus, and access to a faculty member who provides guidance, answers questions, and evaluates their work. Contact between the individual student and the instructor is achieved by one or a combination of the following technologies: telephone, voice-mail, computer conferencing, electronic mail, and regular mail.

\section{Characteristics}

There are no class sessions; students study independently, following the detailed guidelines in the syllabus. Students may interact with the instructor and, in some cases, with other students.

Presentation of course content is through print, computer disk, or videotape, all of which students can review at a place and time of their own choosing. Course materials are used over a period of several years, and generally are the result of a structured development process that involves instructional designers, content experts, and media specialists; not specific to a particular instructor.

\section{Example and Rationale}

The NACTEL Program is an Associates Degree program in Telecommunications offered through the Technology Systems department at Pace University. It is especially designed and open only to employees of four major telecommunications companies in the United States. Students are spread over the country, rarely know personally their classmates, are working full time, and commonly are required to travel as part of their job.

Because of these characteristics of the student audience, flexibility of schedule and location are a must. The granularity on student deliverables is one week, which runs from Thursday through Wednesday. Within the week students may schedule their studies as they see fit. Courses are conducted via the Web using the CourseInfo software. Facilities such as discussion boards, listservs, interactive chats, individual email communications, and outline resources are used at the discretion of the individual instructor. Students never meet their instructors in person, although one-on-one phone conversations may take place as the need arises.

\section{Model C: Open Learning + Class}

\section{Description}

This model involves the use of a printed course guide and other media (such as videotape or computer disk) to allow the individual student to study at his or her own pace, combined with occasional use of interactive telecommunications technologies for group meetings among all enrolled students.

\section{Characteristics}

Presentation of course content is through print, computer disk, or videotape, all of which students can review at a place and time of their own choosing, either individually or in groups. Course materials (for content presentation) are used for more than one semester; often specific to the particular instructor (e.g., a videotape of the instructor's lectures).

Students come together periodically in groups in specified locations for instructor-led class sessions through interactive technologies (following the distributed classroom model). Class sessions are for students to discuss and clarify concepts and engage in problem-solving activities, group work, laboratory experiences, simulations, and other applied learning exercises.

\section{Example and Rationale}

Pace University has recently began (Fall, 1999) a doctoral program, the Doctor of Professional Studies (DPS) in Computer Studies, in which students meet face-to-face as a group at the university for about five weekends (Friday evening and Saturday during the day) per semester. The remainder of each course in the DPS program is conducted via the Web using the CourseInfo software. Facilities such as discussion boards, listservs, interactive chats, and outline resources are used at the discretion of the individual instructor.

The face-to-face weekends are designed to:

- Orient students to the expectations of the courses and the following few weeks until the next weekend meeting.

- Conduct group or student team meetings related to team projects.

- Foster a social and team-building dimension to the program. 
- $\quad$ Provide individualized support to those students who request it.

- Administer examinations under controlled conditions, where required by the instructor.

This approach provides the support and teambuilding activities through the face-to-face meetings, while accommodating the schedules of a busy career-oriented class of working students. Students take courses in a lock-step fashion during the first year of the program.

\section{Model D - Dual Mode, Flexible Delivery}

\section{Description}

While not a true distance learning model, this approach represents a new model of course delivery in which students enrolled in a course may study on campus or off-campus, or elect a mixture of both. This model of learning may better meet the needs of those "increasing numbers [of students] who wish to study while at work, either part time or full time, or who wish to study and meet family responsibilities" [13]. Materials are made available online via the Internet, with some materials being handed out in class as handouts. The course will have a faculty member assigned to teach/facilitate the course regardless of the mode of study that students may elect. Class sessions could vary depending upon institution and course, but may be held in closed laboratories and involve reviewing the material for the week, expanding upon issues of particular interest, possibly marking work on line or students might seek assistance in aspects of the course.

Note that this Model is not one of the three distributed by the Institute for Distance Education of the University of Maryland. Nevertheless, it appears to be a distinct approach that is worthy of consideration and study.

\section{Characteristics}

There are regular class sessions which students may elect to attend, alternatively they may choose to study independently, or a combination of both to suit personal circumstances. The class sessions are intended to support learning for younger or less selfmotivated students, to expand on the online materials available in the course, and to enable students to interact with one another and their teacher.

Materials related to the course - schedule, assessments, learning resources and reference materials, are available via the web. These are used over a period of more than one semester.
Assignments are normally submitted online for grading by the facilitator.

The content based material is normally supplemented by various forms of communication student - teacher, student - student, with private and shared spaces supporting both the task related and social aspects of building active learning communities (e.g. email, listservs, discussion forums, telephone and other forms of conferencing).

In this model the course runs to a set schedule (common start and end times) but it could be extended to support continuous enrolment and study, with non face-to-face students each at different stages of the course.

\section{Example and Rationale}

The course "Learning Programming Through Using Visual Basic for Games" offered at Pace University in New York City is an example. This course was a graduate course in "modern", that is, event-driven, graphical programming, for information systems graduate students. It was offered as an intense 3week course over the winter intercession. The course could be characterized as Model C, with the important feature that some face-to-face sessions were optional. The course was primarily project based, with students required to design and build 4 games based on preparatory material given in a printed text. The students had some choices among a set of games and also considerable latitude in terms of the design.

The choices were:

- The dice game of craps

- Hangman or mixed up paper dolls

- Cannonball (basic ballistics animation with hitting of target)

- Enhanced version of Cannonball or Tic Tac Toe or Minesweeper)

The textbook and the face-to-face sessions attempted to engage the students in discovery of critical issues of data representation, logic and interface design in order to be able to develop their own strategies and plans for other, challenging problems. The optional sessions, opportunity to post questions and also send e-mail, and the choices provided for the games all supported individualization of teaching with the teachers (there were two) as resources. Therefore we would categorize the course as tending towards a constructivist approach, cognitive psychology with the development of mental models, generative user activity, etc. If the class were longer, we would have encouraged or perhaps even required teams to work on the larger projects, both to give students 
experience with teamwork and also to produce more significant output.

\section{Cases: Internet Alive and Webalive}

It is often the case that a course does not fall strictly within the guidelines of one of the models, but takes on characteristics of two models. Here are two such courses developed at Auckland University of Technology. They both are based upon the concept of actually using the Internet to teach Internet related concepts.

\section{Internet Alive}

Internet Alive was designed as a distance learning course to teach introductory Internet concepts to a distance community throughout New Zealand. This was a non- traditional audience for the University and the computing group who had been predominantly an on-campus learning environment. When initially launched in 1997 the Internet Alive course was offered in conjunction with Television New Zealand who ran an educational TV series containing a weekly programme introducing viewers to the Internet. Our course ran in tandem with the television programme, and learners would work through the course week by week to keep up to speed with the series. The weekly television programme offered a useful checkpoint to keep students on track with the course. Key components of the course were static web content pages with a course outline and assessment programme; course material broken into a series of week by week lessons; online automatically marked self test quizzes to enable students to test their knowledge; a project requiring students to learn elementary HTML and build a homepage, and a research project into security issues using the internet as a reference source. The results of these assignments were submitted as web sites established on the Linux and Apache server supporting the course. Supplementing these resources were facilities to support communication, an email listserv for students to communicate with their peers and the course facilitator, and direct email from students to lecturer. In later iterations of the course a further café style listserv has been added to enable students to chat together and build an informal online community. Typically each semester's iteration of the course has had 100 - 150 enrolled students.

"An interesting observation from our first online distance course was that students after working together and communicating online, chose to meet face to face in their local towns in New Zealand. When the Auckland group arranged to meet, our lecturer was faced with the dilemma of whether to go along too - but declined. He reasoned that he had been unable to attend sessions in the other towns, he had not been specifically invited, and this was basically a student directed learning activity. In fact the listserver became so active, that at the end of the course over the summer break we kept it going on student demand. Once we closed it down the by now ex-students went on to set up their own!! We have subsequently established a further listserv called "grads" for graduates of the online courses. At times this becomes an extremely active list, and a huge diversity of topics is discussed. These experiences very powerfully demonstrate the concept of education as an intensely social activity, which involves dialogue. Students engage in education to meet social as well as learning needs. The cyber experience is merely the introduction to the closer encounter" [4].

\section{Webalive}

Webalive was a follow up course offered partly to meet demand from students of the Internet Alive course. This course launched in semester two 1999 adopted a different approach, attempting to move beyond the approach of relatively static webpages for content delivery in Internet Alive to a more resource based approach using the internet as a supporting resource for the course. This in itself proved a challenge given the volatility of web resources. We actually had to delay launch of the course by a semester. This was partly due to over optimistic development estimates on the part of the team. But shortly prior to delivering the course our testing had discovered problems with the web resource links. Several links had become obsolete, but even worse many had now become "pay-perview", which would have required students to pay additional costs to third parties to complete the course. The Webalive course covers a range of topics including concepts of e-commerce, elements of multimedia and web site design, text, fonts, graphics, color, etc. and emerging internet technologies such as XML. As part of their assessment students progressively develop a simple electronic shopping website from pre packaged components. Again communication aspects are supported by a combination of listservs and email as for Internet Alive, but with additional supporting features including a discussion forum and a resource database to which students can add their own websites of interest for others to view. Thus it is intended that students become active participants in creating and developing the course content.

This course has a more sophisticated distance learning audience than the Internet Alive course, with most students being in full time work, often in quite high-powered jobs. While the Webalive course is offered in "independent learning" distance 
mode (Model B), the course has been designed to support on campus students also who learn in "dual mode, flexible delivery" (Model D).

One mistake we did make was to mix the two student communities by enrolling the overflow from our on campus courses into the distance version. The disparity in the student bodies proved problematic. Immature students needing the social support and enforced structure of the on campus course (or what might be termed the "structured bullying" of the teacher guided learning experience) bombarded the listservs with inane drivel, which infuriated the mature and more serious students. We are more careful now not to mix the student bodies after this experience. The rough justice of closing down a listserv for a week or two to calm down immature on campus students is not an appropriate mechanism for more discerning audiences. It is also important to us that the virtual communities created as part of these courses become a mutually supportive body of peers. Among other things this has the added benefit of reducing the load on the course facilitator as students rely on one another for assistance.

One general comment to make regarding these courses, is that while they have been very successful and highly regarded by students, they have imposed a heavy toll on the course developers. They have involved large amounts of hand crafting, using web development tools and raw HTML, detailed research to gather and distil materials for presentation, time to develop quizzes and the case study site, and are "early adopter" rather than fully scalable models of course delivery over the web. However they are tailored, very specific courses with significant and valuable functionality, which do meet the need.

\section{Potential of Distance Learning for Computing Education}

Computing is now a broad, complex field. Educating people in and for this field has its own challenges independent of the advantages and disadvantages of distributed education.

The authors conducted an informal survey of participants at the ITiCSE 2000 conference. Respondents were asked the question:

"Independent of form of instruction, what do you think are the top 3 challenges in teaching and learning?"

This resulted in the following set of themes being identified.
- $\quad$ Training vs. Education/ Consumerism

- Accommodating Diversity \& Individual Needs

- Efficient Use of Resources

- Maintaining Discipline Currency

- Effective Teaching/Learning Practices

- Motivating Students

- Flexibility in Delivery

The chart (cf. Figure 1) in Appendix depicts the number of responses $(n=18)$ within each theme.

We now explore what opportunities there are for distance learning to improve computing education. We start with describing aspects of computing that are particularly advantageous for these models of teaching and learning, indicate some general reasons to change and then move on to how some, though not all, of the challenges indicated above may be addressed.

\subsection{Advantages from Nature of Field}

The field of computer education appears to have certain built-in advantages for making use of distributed education. An obvious advantage is that students in computing generally come with a basic level of computer literacy. If they do not have at least minimal skills, they are willing to take the time to acquire them.

A more subtle point is that taking the time to learn the mechanics of the delivery system is not judged by students or other stakeholders such as parents or administrators to be wasted time, but time "on-task." Communicating via the Web or similar media would be something to be done with work colleagues and clients and so practicing would be deemed worthwhile. More generally, using technology to learn about technology seems fitting. This would not be the case in other disciplines.

The above two points about students have comparable points about faculty. Developing materials is a tremendous job. However, computing faculty can acquire or already have the skills to do so, even if it requires knowledge of special authoring systems. In many cases, the faculty can use the time to study the communications and multimedia technologies. Computing faculty can even spend time creating new tools for authoring, which may be a diversion of effort.

Numerous on-line communities, with rich and current expertise and resources already exist. This enables sharing of materials for a dynamically \& rapidly evolving field. The communities include academic ones, with syllabi, lessons, and schedules; on-line journals; listservs, and so on. Overlapping with the academic communities are large and varied groups of practitioners (system designers and 
builders) who share problems and solutions on technical issues. The open source movement can be viewed as a powerful community. Lastly, communities exist supported by companies. These include ad-based journals such as webmonkey that provide short tutorials. Though one can argue that these organizations provide training as opposed to education, the fact that so much material and discourse is available on-line and used by professionals provides support and motivation to build on-line resources for formal education.

Many courses and topical areas in computing have projects as the appropriate assignment and project work as the natural form of instruction. For example, computing students produce programs, system designs, entity-relationship diagrams, data flow diagrams, class association diagrams, Web pages, etc. This means that individual students or groups do spend much if not most of their time in more-or-less self-directed activity. The aim is to produce an artefact such as a program or a component of a system or a design in a formal language. Forcing (guiding) students to communicate via text in e-mail or discussion postings about the project; submitting a draft or version for review; accepting reviews and revising and then submitting the final form constitute a process that helps develop care and precision in written expression and communication using textual and graphical objects. It is generally supported by the software, sound pedagogically and good professional practice.

Joakim von Wright [17] has termed computer science "intensive" as opposed to "extensive". He describes the latter as referring to subjects in which people read materials and then discuss the content. In computer science, the objective is more to work to understand something, generally by producing something. Constructivist theory [also referenced by Rosbottom, et al in ITiCSE 2000, 13]) would claim that all learning requires "making something", that is, learners learn by constructing new meaning out of prior knowledge, materials they read and see and hear, and collaboration. In any case, this intensive nature of much of computing work may serve as a reason to use distance-asynchronous methods because: these modalities encourage and depend on students having specific, substantial, concrete assignments to work on individually or in assigned groups; generally, at least some of the communication is restricted to text and graphics, and so students cannot rely on hand waving.

\subsection{How Distance Learning Helps Address Specific Challenges}

We do not believe that distance methods can support increasing the number of students that a faculty member can teach for a given class. This is an important point to communicate to university administrators. There have been reports for example, [17] that the student/teacher ratio may even need to decrease. However, the distanceasynchronous methods can expand access to different types of students and also students in different stages of their lives (for example, working full-time, working when much travel is required, raising children) and careers and this can have very positive effects. The distance-asynchronous methods can also support teachers working remotely and so may increase the numbers of faculty pool.

The existence of varied models of learning such as collaborative learning communities may mean that the student/teacher ratio is not significant for all courses. We do not believe that teachers and teaching goes away for serious education, but the mathematics and economies of scale may change.

Hybrid and asynchronous models provide ways for all or at least more to contribute. Shy people, people not confidant about their speaking, are allowed the time and space to present themselves in careful and deliberate ways. Appearances are less important. Small numbers of students cannot dominate the discussion. Teacher needs to work to make this all happen but the technical support is generally present.

\section{Flexibility}

There is however, some evidence that distributed education may prove effective means of supporting female participation in computing. For instance Smythe [15] found "little discrepancy between the sexes with $36 \%$ of males and $31 \%$ of females having used the Internet." Young et al. [19] found that in a flexible delivery hybrid model (Model D) online courses especially suited mature females who were simultaneously juggling the needs of family, work and study. It offered them the flexibility to study at their own time, often from 10:00 pm onwards when family chores were done and children were in bed.

Increasing diversity in the computing student body brings with it "changing modes of study: more reeducation, more mature students, more non-majors, more hybrid degrees and study programmes" [5]. Learning in the computing field is ongoing for life, not a static process to be completed by the achievement of a degree. Life long learning is considered a worthy goal for psychological as well as vocational reasons. Because technology is constantly evolving, many experienced people in the field feel a need and a desire to avoid falling behind in terms of skills. It is the hope of those in academia 
that there is a theoretical foundation that is not changed by every new invention. Nevertheless, there are new products and also new paradigms. There is also a need for many practitioners to become students once again to open up opportunities for personal and professional advancement. This all creates demands for educational services for continuing education. More flexible modes of delivery that better accommodate the needs of part time students and those in full time work are required. The modes of study discussed here may prove part of the answer.

\section{Programming in the Small}

Acquiring the skills and habits of mind to take a problem, perhaps even an open-ended problem, and formulate a solution in terms of logic, user-interface, and role in a larger system is a daunting task. However, as we have indicated, the constraints of distributed systems may be supportive and even facilitating of the effort. These programming in the small are often individual efforts that really should not be fixed in time and space. They are selfdirected.

As was indicated above, the deliberate pacing of interactions in asynchronous and hybrid courses encourages processes in which students first communicate in text about their project, then produce draft solutions, present their solutions for review, revise and then polish and produce the final form, or at least the next version. This is similar to what is called the writing process or writing for publication in composition and has considerable merit because it resembles the professional way of doing things. It can also reflect the software process with enforced checkpoints and reviews, which further encourage the production of high quality materials.

The use of visualization seems especially beneficial for computing topics. This can include things such as desktop audiographics during an Internet lecture [10], lecturelets, small expositions with animation done through Java applets, with audio [6], automatic generation of problems [9], and animation for demonstrating algorithms and presenting pieces of programs [8,12] and other papers in the Visualization session at ITiCSE 2000), and digital (Quicktime) movies for student interaction with algorithmic visualization [2]. These techniques require making greater demands on resources such as the student's computer and Internet connection, but they have real potential to aid student learning and the reports are positive. In most cases, students can view and work with these materials over and over again. In some cases, students even change the materials, invoking even deeper potential learning.

\section{Programming in the Large}

What is termed programming in the large implies large[r] projects, collaboration with other students, and, perhaps, interactions with other people, commercial sources, and existing operational resources. Each of these things is encouraged by a mode in which time and space is flexible. The ability to work effectively as a member of a team is a key professional capability of software developers [3]. Therefore, creating educational contexts which reinforce this capability are an important element in a computing curriculum.

Setting up teams initially and the working of teams can be difficult when everyone is not together in one place. However, overcoming difficulties can be an educational experience. In the working world, people need to solve the problem of making connections with others.

Requiring large[r] projects and assigning teams are mutually supportive. A team can be expected to do more and a large project may require a team. Teamwork in an educational setting does not mean that the team needs to be physically together in time and/or space all the time just as it does not mean that in a work situation. Students do need to work out how to manage the collaboration.

Students can make use of the on-line communities to complete their projects. This is an appropriate way of working. Of course, just as composition teachers must be more inventive and not assign students topics for which they can obtain a completed essay on-line, computing faculty need to be inventive about the assignments and the requirements for presenting the final work. If a student or a team learned from other sources how to do portions of the project and can now explain how they did it, they do deserve at least some credit, perhaps all. Assessment is not trivial, but there are solutions.

\section{Technical Communication}

Some students appear to come to computing to avoid oral and written communication. Since these are an essential part of any career in computing, anything that requires and supports communication tasks is strongly beneficial. The asynchronous and hybrid forms do this.

In most cases (assuming the course is not entirely teleconferenced and the use of even audio conferencing is limited), students must make use of text and graphics that they produce. This means they are writing! Moreover, there can be a systematic progression from informal to formal, from e-mail and sketches to formal diagrams (data 
flow diagrams, ER diagrams, object class association, use case, etc.) Even in the case of video and audio conferencing, we believe that students will take a responsible, deliberate attitude towards presentation of themselves and their work.

The gender and minority issues are more complex. Anecdotal reports exist that support the notion that females and the minorities underrepresented in technical careers do better in a situation in which they can present themselves at their own pace and through their work. Such environments also support the learning of non-English speaking background students. Conversely, the development of students' oral communications skills tends to be under emphasized. If this is true, it would be important for these students to participate in situations which require them to development and practice their oral communication and interpersonal skills to help them prepare to make strong, positive impressions face-toface.

\section{Conclusion}

This report concludes that a considered and flexible attitude toward distance and asynchronous learning methods can bring benefits to computer education. A range of forces including increasing demand for computer education, the rise of consumerism, increasing diversity of the student body, and the demands of lifelong learning, and the rapidly changing nature of the discipline demand a set of flexible and well designed responses. In particular, attention to a hybrid model, more Web-supported than Web-based, with provision for student choices in how they participate, seems to have significant potential for improving teaching and learning.

By contrast the Web also presents risks for educators that mere content presentation and information delivery online be misunderstood as education. There are also commercial models of training delivery, which concentrate on delivering consistent packaged units of learning to a standard formula. Therefore, online courses need to be informed by sound principles of pedagogy and well-constructed course design. More constructivist views of learning appear to us to fit the computing field, and we need to incorporate these principles in effective online course design. Lastly, any attempt to adapt new teaching methodologies must address the particular nature of computing, especially the critical components of the field that can be the greatest challenge for teaching. The challenge is not attempt to replicate the standard classroom, but identify those areas where the technology may best support student learning in the online environment.

\section{References}

[1] Alexander, S., Hedberg, J., (1998), An Evaluation Of Information Technology Projects For University Learning, CUTSD, Australian Government Publishing Service, (Executive Summary available online. Retrieved May 13, 2000 from World Wide Web: http://www.iim.uts.edu.au/about/sa_pubs/cautexec.ht $\underline{\mathrm{ml}})$.

[2] Anderson, J., Algorithm Visualization using QuickTime Movies for Student Interaction: Algorithms from Computational Geometry, Poster session, ITICSE 2000, Helsinki, July 2000,

Retrieved July 13, 2000 from the World Wide Web: http://Gershwin.fandm.edu/algoviz/AlgoCompGeom $\underline{01 . h t m l}$

[3] Clear, A. (1998), New Zealand Polytechnic Business Computing Programmes Graduate profiles, New Zealand Journal of Applied Computing \& Information Technology, 2; 1, pp. 118- 130

[4] Clear, A., (1999), Online Education, But is it Education? In Thinking Issues Editorial Column, SIGCSE Bulletin, 31; 4, ACM New York

[5] Daniels, M., Petre, M., Berglund, A., (1998), Building A Rigorous Research Agenda In To Changes In Teaching, Proceedings ACM Australasian conference of Computer Science Education (Brisbane)

[6] Culwin, F., Lecturelets-Web Based Java enabled lectures, Proceedings, ITICSE 2000, Helsinki, July 2000, pp 5-12

[7] Fåhræus, E., et al. Teaching with Electronic Collaborative Learning Groups, ITICSE'99 Working Group Reports, Vol 31, No. 4, ACM. December 1999.

[8] Gries, D., ProgramLive, a multimedia, Javabased LiveText on Programming, Data Desk, Ithaca, NY, July 2000

[9] Kumar, A., Dynamically generating problems on static scope, Proceedings, ITICSE 2000, Helsinki, July 2000, pp. 9-12

[10] Pullen, M., The Internet-based lecture: Converging teaching and technology, Proceedings, ITICSE 2000, Helsinki, July 2000, pp. 101-104

[11] Reeves, T., (1992), Effective Dimensions of Interactive Learning Systems, Keynote address to Information Technology for Training and Education (ITTE '92) Conference, Sept, Brisbane, Australia. [12] Rößling, G., Schüler, M., and Feisleben, B., The ANIMAL Algorithm Animation Tool, Proceedings, Proceedings, ITICSE 2000, Helsinki, July 2000, pp. 37-40

[13] Rosbottom, J., Crellin, J., Fish, D., A generic model for on-line learning, Proceedings, ITICSE 2000, Helsinki, July 2000, pp. 108-111

[14] Siviter, D., Petre, M., and Klein, B., Harnessing technology for effective inter- and intra- institutional 
collaboration, ITICSE'97 Working Group, SIGCSE/SIGCUE ITICSE'97. ACM. 1997.

[15] Smythe, M., (2000) Proceedings of the 13th Annual NACCQ conference, Wellington, New Zealand, June 30 -July $3^{\text {rd }}$ pp. 331-338

[16] University of Maryland Institute for Distance Education, University College, Retrieved on July 11, 2000 from the World Wide Web:

http://www.unuc.edu/ide/ide.html.

[17] von Wright, J., Distance tutorials in a systems design course, Proceedings, ITICSE 2000, Helsinki, July 2000, pp. 105-107

[18] Wolz, U., et al, Computer-mediated communication in collaborative educational settings, ITICSE'97 Working Group, SIGCSE/SIGCUE ITICSE'97. ACM. 1997

[19] Young, S., McSporran, M., Dewstow, R., Who Wants to Learn Online? Proceedings of the 12th Annual NACCQ conference, Dunedin, New Zealand, July 1999. 


\section{Appendix}

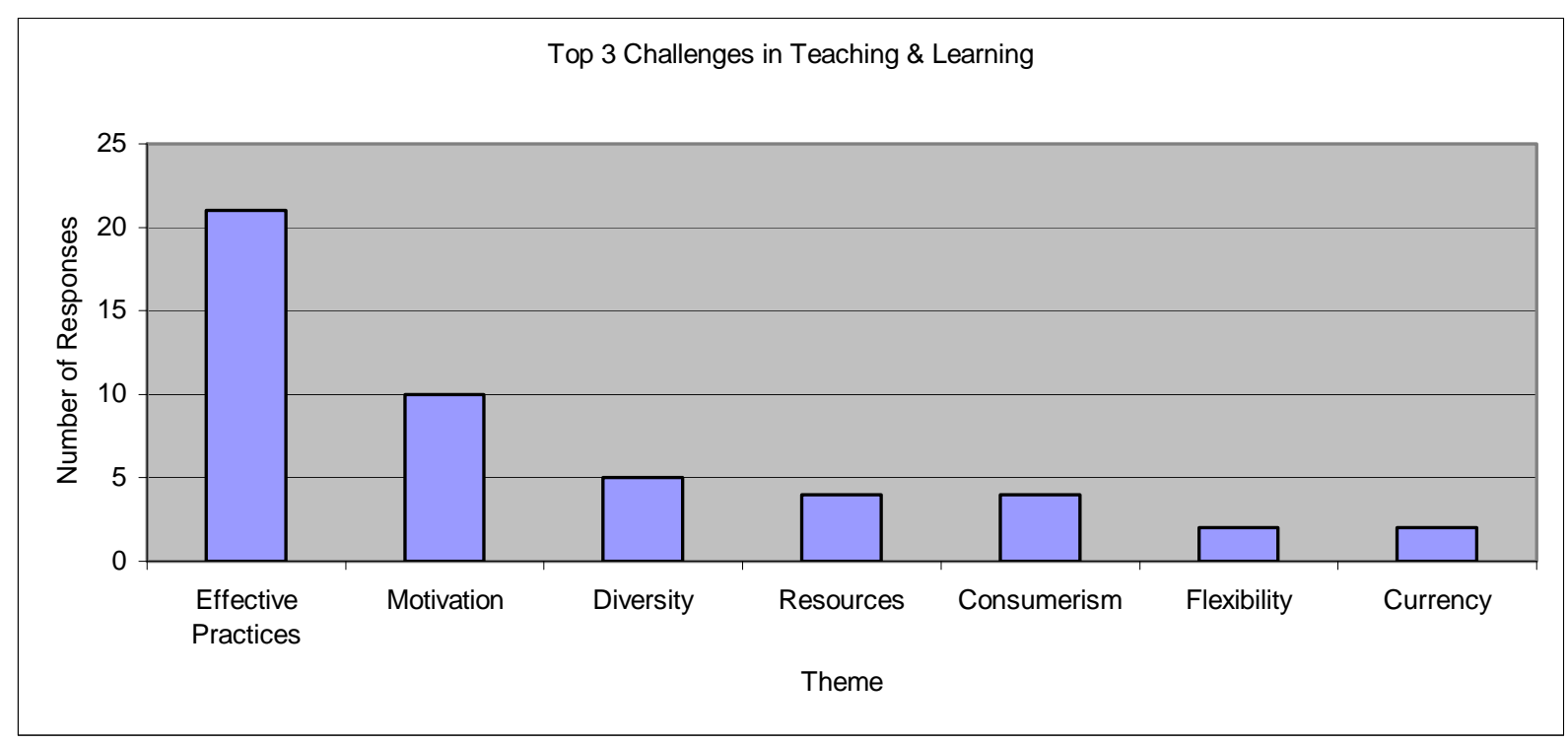

